\title{
Gas Storage Technology Consortium
}

\author{
Technical Quarterly Progress Report for \\ July 1, 2006 - September 30, 2006
}

By

Joel L. Morrison

and

Sharon L. Elder

November 29, 2006

Work Performed Under DOE Cooperative Agreement DE-FC26-03NT41779

\section{Submitting Organization:}

The Pennsylvania State University

The Energy Institute

C211 Coal Utilization Lab

University Park, PA 16802 


\section{DISCLAIMER}

This report was prepared as an account of work sponsored by an agency of the United States Government. Neither the United States Government nor any agency thereof, nor any of their employees, makes any warranty, express or implied, or assumes any legal liability or responsibility for the accuracy, completeness, or usefulness of any information, apparatus, product, or process disclosed, or represents that its use would not infringe privately owned rights. Reference herein to any specific commercial product, process, or service by trade name, trademark, manufacture, or otherwise does not necessarily constitute or imply its endorsement, recommendation, or favoring by the United States Government or any agency thereof. The views and opinions of the authors expressed herein do not necessarily state or reflect those of the United States Government or any agency thereof. 


\section{ABSTRACT}

Gas storage is a critical element in the natural gas industry. Producers, transmission \& distribution companies, marketers, and end users all benefit directly from the load balancing function of storage. The unbundling process has fundamentally changed the way storage is used and valued. As an unbundled service, the value of storage is being recovered at rates that reflect its value. Moreover, the marketplace has differentiated between various types of storage services, and has increasingly rewarded flexibility, safety, and reliability. The size of the natural gas market has increased and is projected to continue to increase towards 30 trillion cubic feet (TCF) over the next 10 to 15 years. Much of this increase is projected to come from electric generation, particularly peaking units. Gas storage, particularly the flexible services that are most suited to electric loads, is critical in meeting the needs of these new markets.

In order to address the gas storage needs of the natural gas industry, an industry-driven consortium was created - the Gas Storage Technology Consortium (GSTC). The objective of the GSTC is to provide a means to accomplish industry-driven research and development designed to enhance operational flexibility and deliverability of the Nation's gas storage system, and provide a cost effective, safe, and reliable supply of natural gas to meet domestic demand. This report addresses the activities for the quarterly period of July 1, 2006 to September 30, 2006. Key activities during this time period include:

- Subaward contracts for all 2006 GSTC projects completed;

- Implement a formal project mentoring process by a mentor team;

- Upcoming Technology Transfer meetings:

$\neg$ Finalize agenda for the American Gas Association Fall Underground Storage Committee/GSTC Technology Transfer Meeting in San Francisco, CA. on October 4, 2006;

$\neg$ Identify projects and finalize agenda for the Fall GSTC Technology Transfer Meeting, Pittsburgh, PA on November 8, 2006;

- Draft and compile an electronic newsletter, the GSTC Insider; and

- New members update. 
TABLE OF CONTENTS

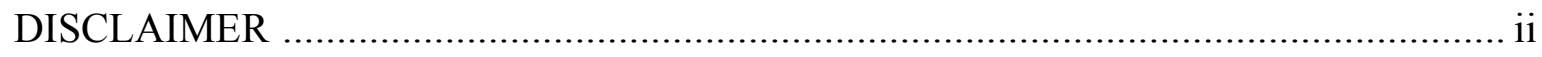

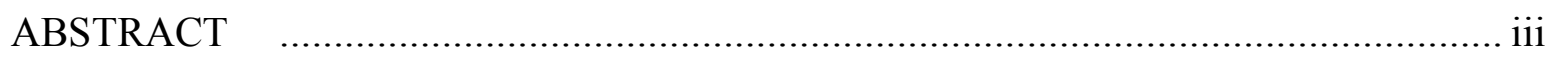

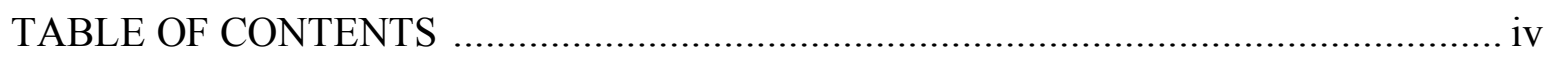

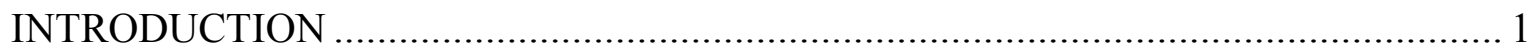

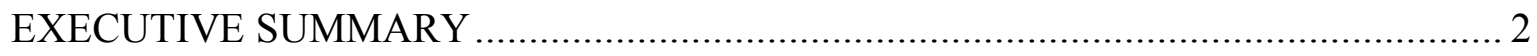

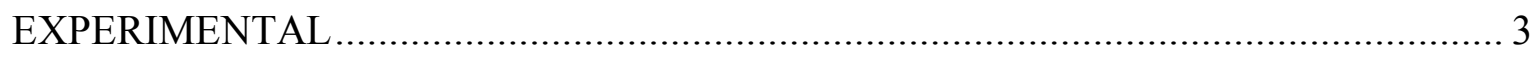

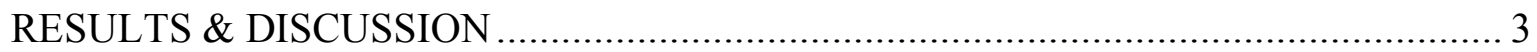

Subaward Contracts Completed for 2006 Projects ............................................................

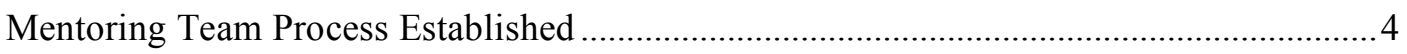

Upcoming Technology Transfer Meetings ....................................................................... 4

GSTC Technology Transfer Meeting, San Francisco, CA.......................................... 4

GSTC Technology Transfer Meeting, Pittsburgh, PA ………................................. 4

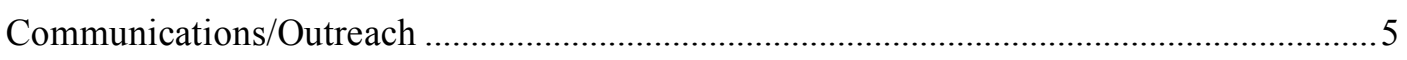

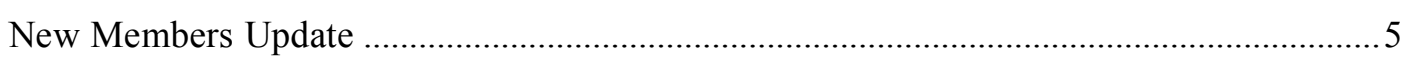

Planned Activities for Next Reporting Period ...................................................................

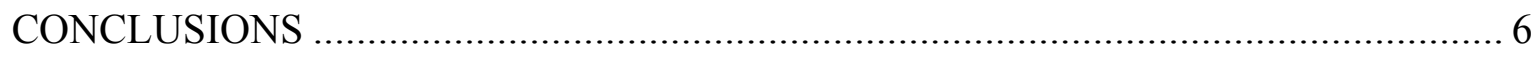

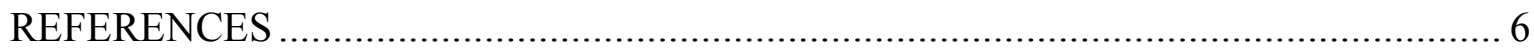




\section{INTRODUCTION}

Gas storage is a critical element in the natural gas industry. Producers, transmission and distribution companies, marketers, and end users all benefit directly from the load balancing function of storage. The unbundling process has fundamentally changed the way storage is used and valued. As an unbundled service, the value of storage is being recovered at rates that reflect its value. Moreover, the marketplace has differentiated between various types of storage services, and has increasingly rewarded flexibility, safety, and reliability. The size of the natural gas market has increased and is projected to continue to increase towards 30 trillion cubic feet (TCF) over the next 10 to 15 years. Much of this increase is projected to come from electric generation, particularly peaking units. Gas storage, particularly the flexible services that are most suited to electric loads, is critical in meeting the needs of these new markets.

In order to address the gas storage needs of the natural gas industry, an industry-driven consortium was created - the Gas Storage Technology Consortium (GSTC). The objective of the GSTC is to provide a means to accomplish industry-driven research and development designed to enhance operational flexibility and deliverability of the Nation's gas storage system, and provide a cost effective, safe, and reliable supply of natural gas to meet domestic demand. Consortium technology development is conducted in the general areas of well-bore and reservoir, operations, mechanical, and salt caverns. Consortium members elect an Executive Council that is charged with reviewing projects for consortium co-funding. Proposals must address improving the production performance of gas storage and must provide significant cost share. The process of having industry develop, review, and select projects for funding ensures that the consortium conducts research that is relevant and timely to industry. Co-funding of projects using external sources of funding is sought to ensure that consortium funds are highly leveraged. 


\section{EXECUTIVE SUMMARY}

This report is a summary of the important accomplishments during the period of July 1 , 2006 to September 30, 2006. The GSTC was established under contract to the Pennsylvania State University from the U.S. Department of Energy (DOE), National Energy Technology Laboratory (NETL) in June 2004. The agreement provides Penn State the overarching management responsibilities for the consortium.

Key activities for this reporting period includes the following activities:

\section{Subaward Contracts Negotiated}

The remaining two subaward contracts for the 2006 projects were completed during this quarter. The GSTC awarded eight projects at the February 2006 meeting, with six subaward contracts completed last quarter.

\section{Mentoring Team Procedure Established}

At the February meeting, the Executive Council suggested a mentor team be created to more closely monitor individual projects, hence being more able to guide the research, making timely corrections and suggestions. During this quarter, a mentoring team procedure has been established. The first conference call is scheduled to take place during the early part of next quarter.

\section{Upcoming Meetings for Technology Transfer}

The full agenda for the Fall American Gas Association Underground Storage Committee/GSTC Technology Transfer Meeting in San Francisco, CA. on October 4, 2006 has been finalized. This meeting will offer technology transfer for the southwestern regions of the US. Six projects will present technical findings during the one-day meeting;

Identify projects and finalize agenda for the Fall GSTC Technology Transfer Meeting in conjunction with PRCI and the Stripper Well Consortium in Pittsburgh, PA on November 8, 2006. Eight projects have been identified to give full presentations and seven of the new 2006 projects will participate in a roundtable discussion. This meeting will offer technology transfer for the northeastern regions of the US.

\section{Communications/Outreach}

Draft and compile a quarterly e-newsletter, the GSTC Insider.

\section{Membership Update}

The GSTC continues to recruit new members. Two new members have been added during this quarter. The GSTC membership now includes a total of 51 members. 


\section{EXPERIMENTAL}

A description of experimental methods is required by the DOE for all quarterly technical progress reports. In this program, Penn State is responsible for establishing and managing an industry-driven underground gas storage consortium. Technology development research awards are made on a competitive basis. Technical reports from the individual researchers are required to contain an experimental discussion section and are submitted to consortium members and DOE for their review. Therefore, this section is not applicable to the Penn State contracted activities.

\section{RESULTS \& DISCUSSION}

This report addresses the activities for the reporting period from July 1, 2006 through September 30, 2006. Key activities during this time period include:

- Complete negotiations and finalize subaward contracts for the two projects that were outstanding from last quarter;

- Implement a formal project mentoring process by a mentor team;

- Upcoming Fall Technology Transfer Meetings:

$\neg$ Finalize agenda for the Fall GSTC Technology Transfer Meeting in conjunction with the American Gas Association's Underground Storage Committee Meeting in San Francisco, CA on October 4, 2006;

$\neg$ Identify projects and finalize agenda for the Fall GSTC Technology Transfer Meeting in conjunction with PRCI and the Stripper Well Consortium in Pittsburgh, PA on November 8, 2006;

- Draft and compile a quarterly e-newsletter; and

- New members update.

\section{Subaward Contracts Completed for 2006 Projects}

During this quarter the remaining two subaward contracts were negotiated and completed. These contracts are for the projects, "Storage Field Wellbore Flow Data Containing Water and Hydrates", Colorado Engineering Experiment Station (CEES) and 
"Protocol Evaluation for Scale Prevention and Remediation in Gas Storage Reservoirs and Formulations", Colorado School of Mines (CSM). The subaward contracts for all eight projects awarded at the February meeting are now completed.

\section{Mentoring Teams Process Established}

At the February 2006 Executive Council (EC) meeting, the EC discussed establishing formal mentor teams to make sure projects are on-task and on-track. Several GSTC members have agreed to monitor specific project(s) and offer feedback to the PIs. A formal mentor team protocol has now been established whereby the quarterly reports submitted by the PI are posted to the GSTC website; mentors are notified and are given two weeks to view the reports. At the end of the two weeks, a conference call will be arranged among the mentor team, the GSTC Director, and the PI for the project.

The Predicting and Mitigating Salt Precipitation (Correlations Co.) project has been identified as the first project to complete the procedure. The conference call has been scheduled for early in the next quarter.

\section{Upcoming Technology Transfer Meetings GSTC Technology Transfer Meeting, San Francisco, CA} The southwestern US, Fall GSTC Technology Transfer Meeting will be held at the Serrano Hotel in San Francisco, CA in conjunction with the American Gas Association (AGA) Underground Storage Committee Fall Meeting on October 4, 2006. Six projects have been identified for technology transfer presentations. Following the technology transfer meeting, the GSTC administration will join AGA in a tour of the Pacific Gas and Energy underground gas storage fields located on McDonald Island approximately 10 miles west of Stockton, CA.

\section{GSTC Technology Transfer Meeting, Pittsburgh, PA}

The second GSTC Technology Transfer Meeting will be held in the northeastern US at the Embassy Suites Pittsburgh International Airport Hotel, Pittsburgh, PA on November 8, 2006. Eight projects will deliver technology findings, along with 
a roundtable discussion from seven of the new 2006 projects. The meeting will be in conjunction with the Pipeline Research Council International (PRCI) Underground Storage Technical Planning Committee meeting and the Stripper Well Consortium (SWC) technology transfer meetings. The PRCI meeting will be on November 7, 2006. The GSTC will host a joint GSTC/PRCI reception following the close of the formal PRCI meeting. A SWC/GSTC joint reception, exhibit, and poster session will be held on November 8, 2006, following the close of the formal GSTC meeting. Ten projects from GSTC and SWC will showcase technology during the exhibit session. The SWC Technology Transfer Meeting will follow on November 9, 2006. The scheduling of back-to-back meetings will fit with the plans to strengthen the interactions between SWC, GSTC, and PRCI. This will expand the cross-fertilization of the two consortiums and allow delegates to conveniently attend all meetings.

\section{Communications/Outreach}

The quarterly newsletter, the GSTC Insider, has been drafted. The newsletter serves as an information dissemination tool for upcoming events, project progress, and information important to the gas storage industry.

\section{New Members Update}

The GSTC membership continues to grow and broaden in diversity. During this quarter the following were added:

- Dominion Delivery, $\mathrm{OH}$

- C-FER Technologies, Alberta, CA

The membership for 2006 now includes 42 full, 7 university and 2 affiliates for a total of 51 members. Recruiting additional members throughout 2006 will continue.

\section{Planned Activities for the Next Reporting Period}

During the next quarter the GSTC will:

- Host the southwestern US Fall GSTC Technology Transfer Meeting in San Francisco, CA; 
- Host the northeastern US Fall GSTC Technology Transfer Meeting in Pittsburgh, PA;

- Identify project mentor teams, then schedule and continue mentor team conference calls for 2006 projects;

- Recruit and invoice membership for 2007;

- Solicit nominations for (4) Executive Council seats;

- Draft and release the request for proposals (RFP) for 2007;

- Continue new member recruitment;

- Draft and release another online newsletter; and

- Continue to update and improve the GSTC web site.

\section{CONCLUSIONS}

During this reporting period, the GSTC negotiated the final two outstanding subaward contracts for the projects identified at the February meeting. The GSTC prepared for two regional technology transfer meetings, one in the southwest (California region) and one in the northeast (Pennsylvania region) in the October/November time frame. A project mentor team procedure has been implemented for the 2006 projects. The GSTC added two new members during this quarter. The GSTC has laid a solid foundation for continued membership growth and industrial-relevant technology transfer.

\section{REFERENCES}

A listing of referenced materials is required by the DOE for each quarterly technical progress report. This technical progress report for the GSTC did not utilize any reference material during this reporting period. 